\title{
Unilateral retinitis pigmentosa sine pigmento
}

\author{
JEROME T. PEARLMAN, JOAN SAXTON, AND GARY HOFFMAN \\ From the Department of Ophthalmology, Visual Physiology Laboratory, Fules Stein Eye Institute, \\ UCLA School of Medicine, Los Angeles, USA \\ AND \\ STANLEY CARSON \\ From the Department of Ophthalmology, USC School of Medicine, Los Angeles, USA
}

At the Fourth ISCERG Symposium, held in Hakone, Japan, in 1966 Straub (1966) reviewed the subject of unilateral retinitis pigmentosa and made a number of important observations. Up to then only 34 cases of unilateral retinitis pigmentosa had been reported. Only one of them was of unilateral disease without pigment (Jacobson and Stephens, 1962). Rickers and Domarus (1974) stated that nearly roo cases of unilateral retinitis pigmentosa had been described since the first report in 1865 . They thought that the diagnosis could be verified in only about 20 cases.

Straub emphasized the clinical value of electroretinography (ERG) in establishing the truly unilateral nature of such cases, indicating that the ERG response must be normal in the unaffected eye. Others have long recognized that many cases of supposed unilateral retinitis pigmentosa were actually instances of highly asymmetric bilateral disease in which the 'normal' eye eventually showed the disorder, but only much later. Franceschetti, François, and Babel (1963) showed that the ERG response in such cases was impaired in both eyes. This significant clinical feature distinguishes genuine unilateral disease from 'pseudounilateral' (that is, asymmetric bilateral) retinitis pigmentosa.

Henkes (1964) found that the electro-oculogram was bilaterally disturbed in many instances of presumed unilateral retinitis pigmentosa but normal in the unaffected eye in truly unilateral cases. Thus measuring the resting potential of the eyes as well as the ERG is of value.

If unilateral retinitis pigmentosa is uncommon, cases without pigmentation are even rarer. We report here a case of unilateral retinitis pigmentosa sine pigmento.

\footnotetext{
This study was supported by NIH grant EYoo33 I from the National Eye Institute (Bethesda, Maryland) and from the private contributions of the Sklar and Phillips Families (Shreveport, Louisiana)

Address for reprints: Jerome T. Pearlman, MD, Jules Stein Eye Institute, UCLA School of Medicine, Los Angeles, California
} 90024

\section{Case report}

A 27-year-old White woman was first seen at the Jules Stein Eye Institute on 7 March 1974 complaining of seeing spots before the left eye for the past three weeks. She was taking oral contraceptives, but otherwise her past medical history was normal. There was no family history of consanguinity. Childhood diseases included measles, mumps, and chicken pox. Her serology was normal. She did not complain of the right eye and of only minimal symptoms in the left. Unaided visual acuity was $20 / 20$ in each eye, and she did not wear spectacles.

The findings on external examination were within normal limits. Slit-lamp examination showed nothing but a number of dot-like opacities in the anterior vitreous of the left (affected) eye. Initially, these dotlike opacities were thought to be evidence of an inflammatory aetiology of this condition. Such opacities, however, exist in the vitreous of patients with tapetoretinal degeneration (Berliner, 1949). Their absence in the unaffected eye was interpreted as additional evidence of the unilaterality of this patient's disorder.

\section{Ophthalmoscopy}

The fundus of each eye was examined through pupils dilated with I per cent tropicamide and Io per cent viscous phenylephrine hydrochloride ophthalmic solutions (Fig. I). The left eye showed some haziness of the vitreous; much attenuated retinal arterioles; and a subtle, patchy retinal pigment epithelial disturbance in the midperiphery. There was no convincing pallor of the left optic nerve head. The right fundus was normal. No pigmentary changes of salt and pepper or bone corpuscle type were noted. Intraocular pressure by applanation tonometry was $16 \mathrm{mmHg}$ on each side. Special tests consisted of fluorescein angiography, Kodachrome fundus photography, colour vision tests, Goldmann fields, dark adaptometry, electroretinography, and electro-oculography.

Fluorescein angiography of the left eye showed a significant delay in the appearance of dye in the vascular tree relative to the right eye, with considerable attenuation of the retinal arterioles. Even the veins were of smaller calibre. Compared with the right eye, there was a striking hyperfluorescence on the left side in the late 


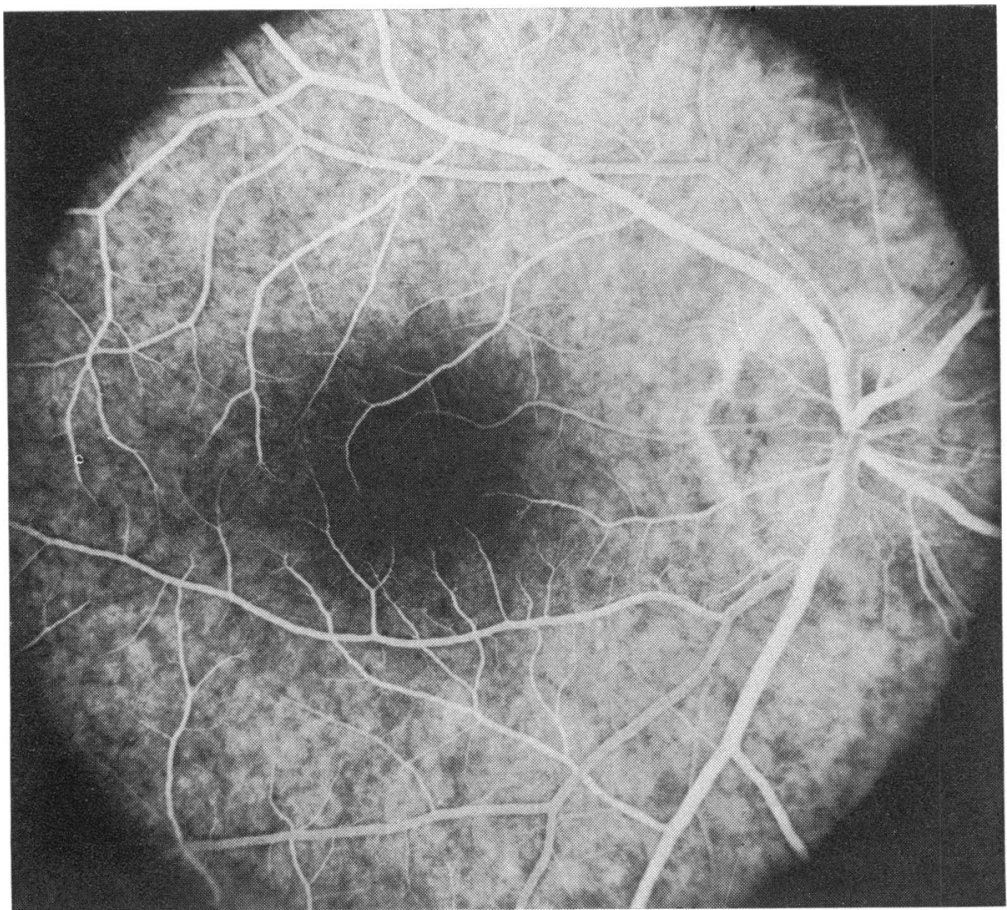

FIG. 2 Fluorescein fundus angiograms

(a) Normal right eye 25 seconds after injection of dye

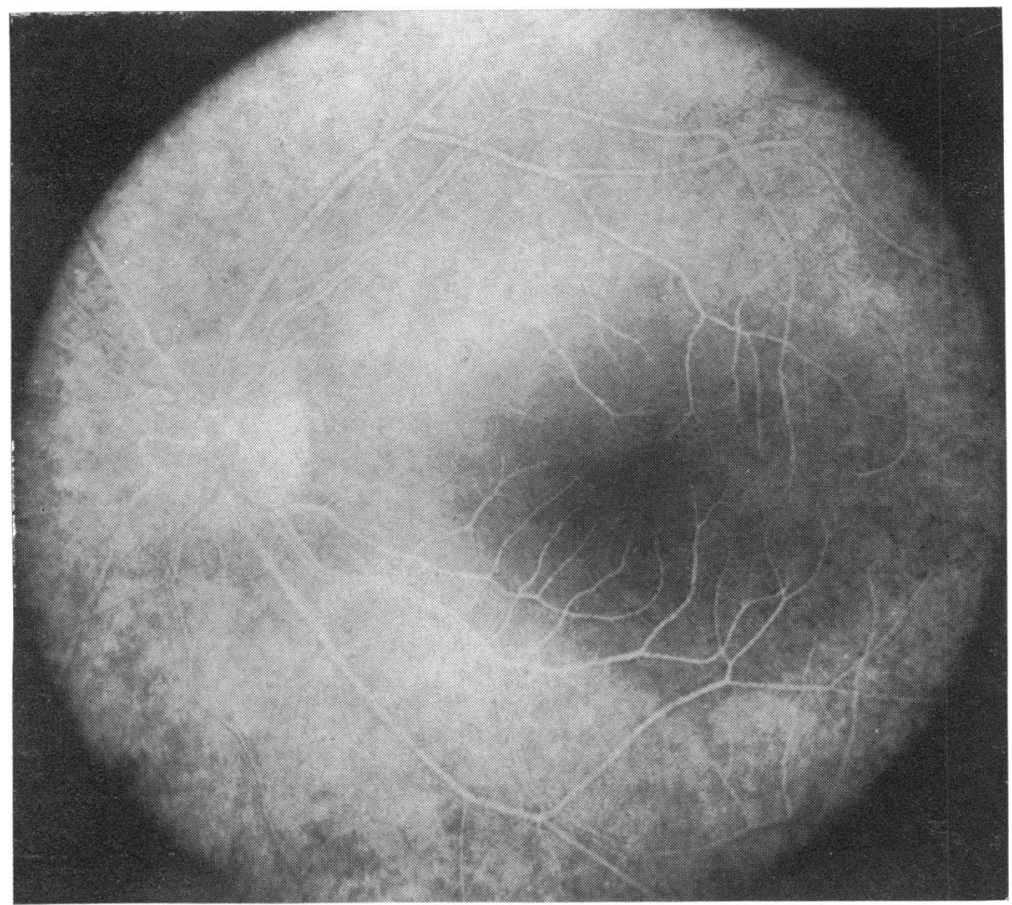

(b) Abnormal left eye 23.8 seconds after injection of dye. Note unusual degree of choroidal hyperfluorescence surrounding darker, central macular area, indicating diffuse abnormality of retinal pigment epithelial layer

phase. No macular disturbance was noted, even on magnification. Fixation was normal (Fig. 2b). A similar study of the right eye showed a normal transit and late phase (Fig. 2a).
Colour vision was normal in both eyes when tested with AO H-R-R and Ishihara pseudoisochromatic plates. No mistakes were made. Goldmann fields of the right eye were within normal limits; those of the 


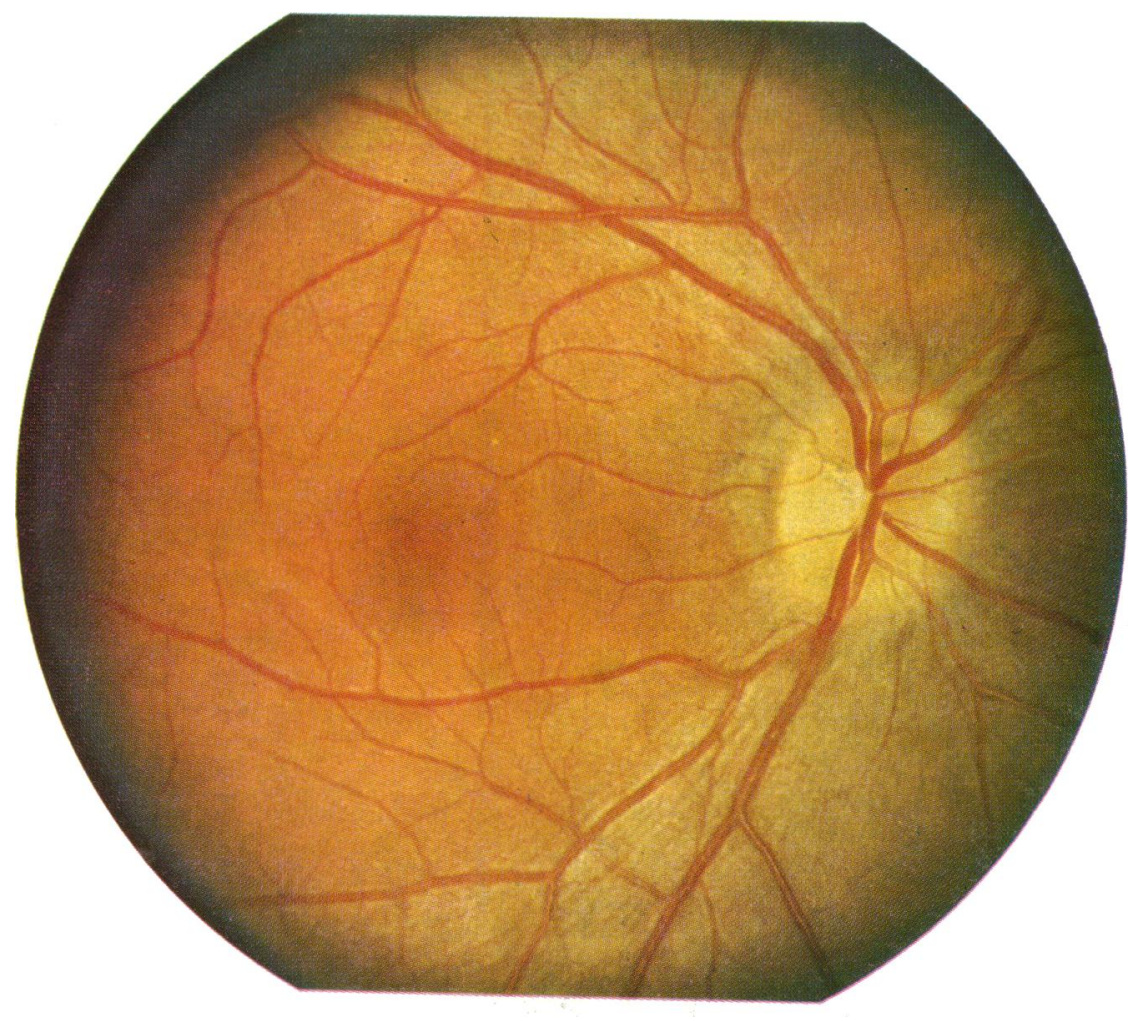

FIG. I Fundus photographs

(a) Disc and macula of iे normal right eye

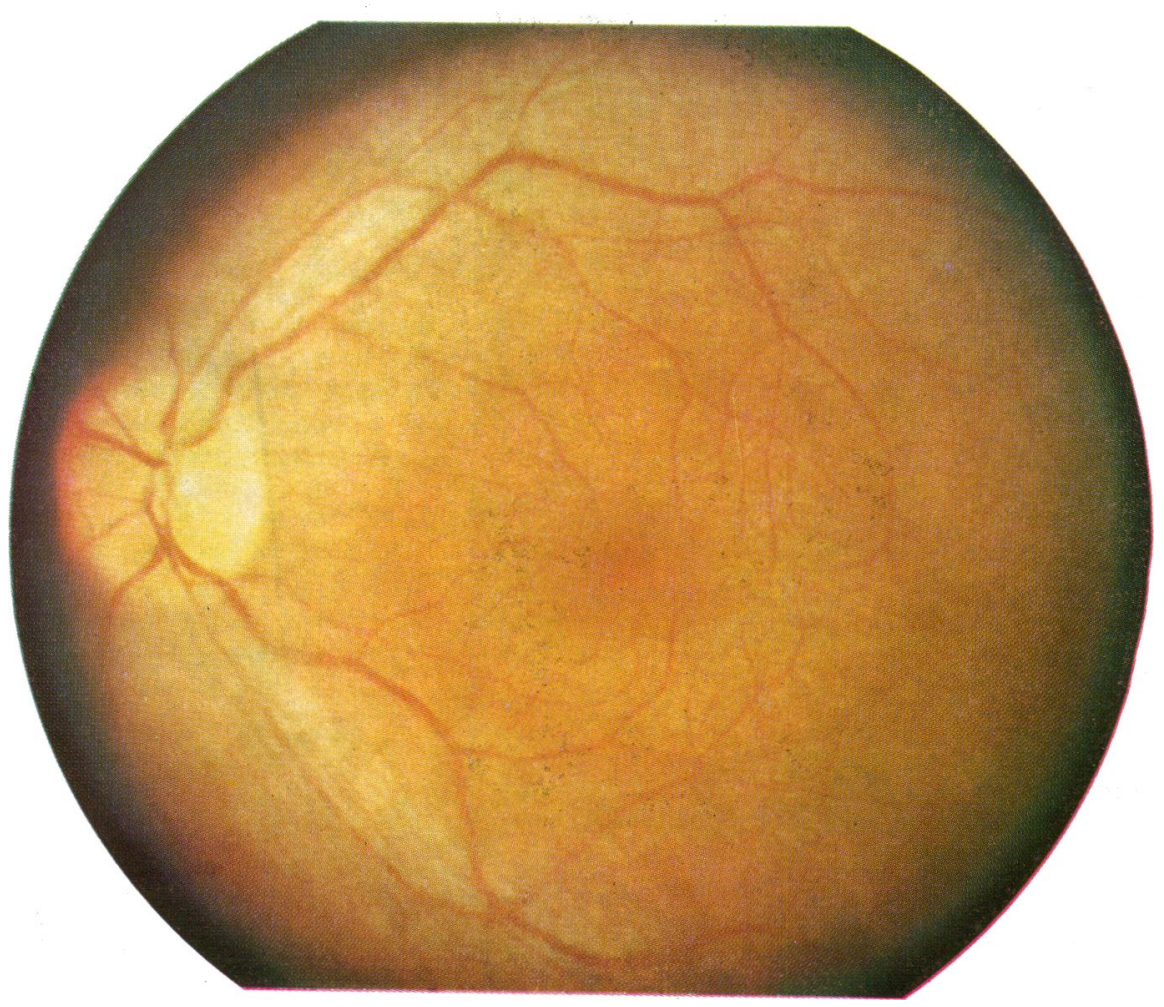

(b) Disc and macula of affected left eye. Note absence of significant optic nerve pallor and presence of much attenuated retinal arterioles

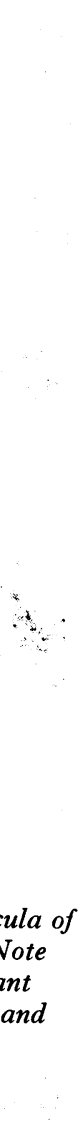

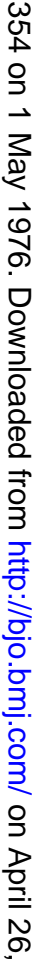


(c) Periphery of normal right eye

(d) Periphery of abnormal left eye showing mottling in retinal pigment epithelial layer. No bone corpuscular pigment was seen anywhere in left fundus

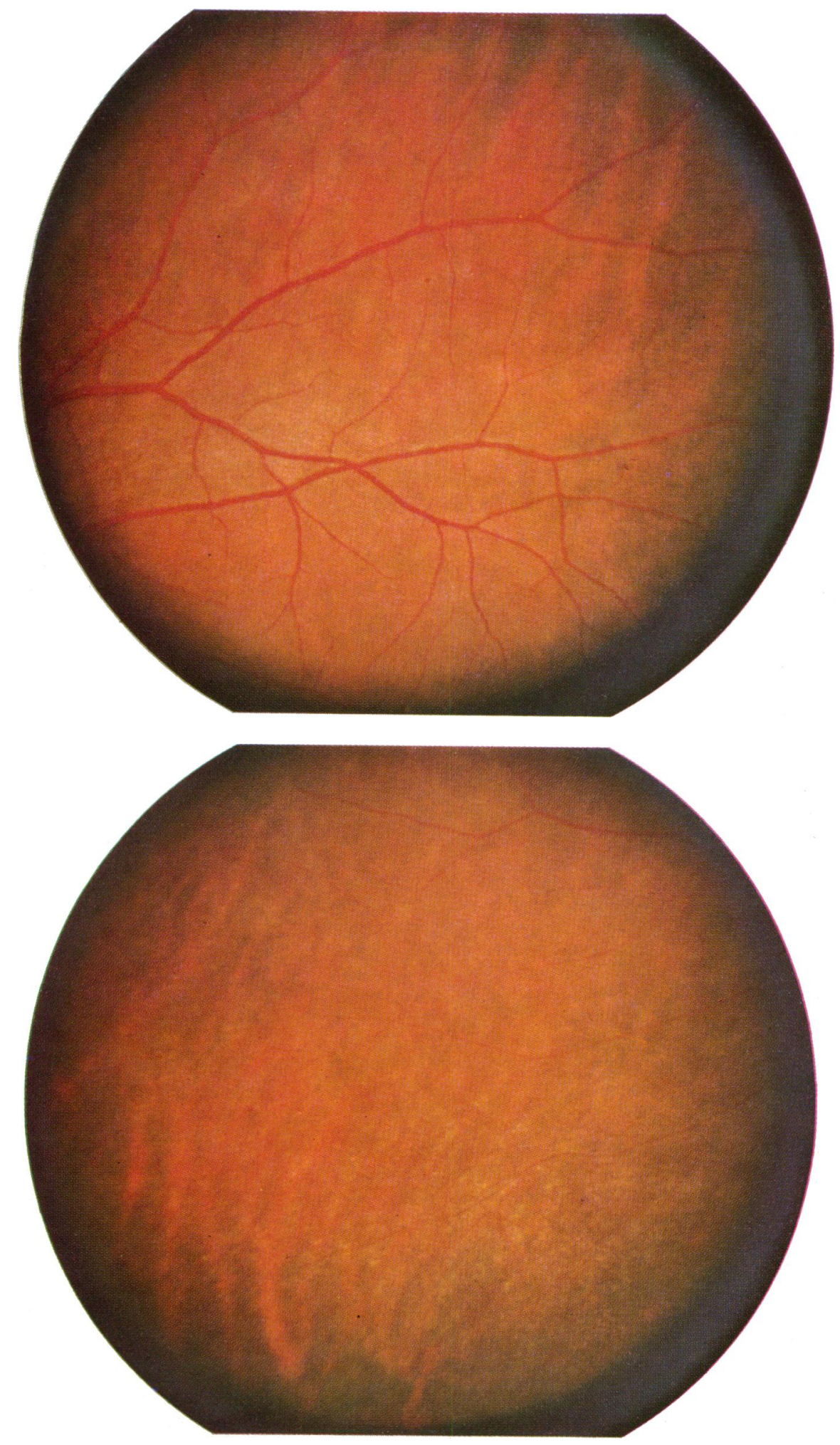




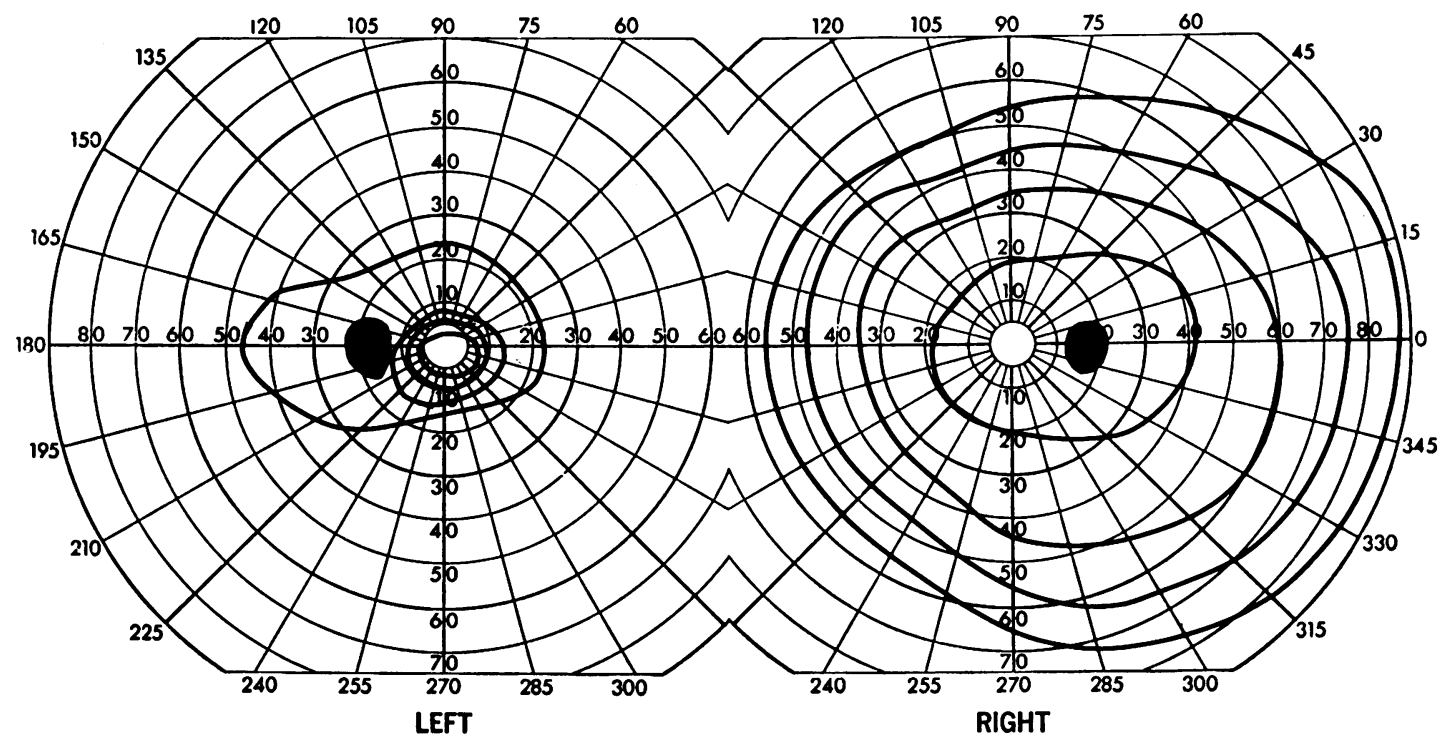

FIG. 3 Goldmann fields of normal right eye and abnormal left eye. Note constriction of all isoptres in OS and the absence of central scotoma. Largest isoptre is $I V-4$; next is $\mathrm{I}-4$; next is $\mathrm{I}-3$; and smallest $\mathrm{I}-2$ on the Goldmann perimeter

left eye showed pronounced constriction of the peripheral field compared with the right. The I-2 isoptre of the left eye was reduced to about six degrees (Fig. 3).

\section{Dark-adaptation studies}

Dark-adaptation studies were made with the GoldmannWeekers adaptometer with a one degree test object flickering on and off at one-second dark and light intervals. The test spot was located $5.5 \mathrm{~cm}$ below the fixation point on the instrument, and thus projected I I degrees above the fovea on the subject's retina. Each test was conducted in the standard manner with pupils dilated by tropicamide I per cent and phenylephrine hydrochloride ro per cent viscous ophthalmic solutions. The subject was exposed to pre-adapting illumination of 18 lux ( 2800 abs) for five minutes. Each test lasted a total of 45 minutes. The tracings showed a normal cone onset for both eyes and a normal development of the rod portion of the curve for the right eye. The left eye showed an abnormal rod development and a raised threshold, beginning at about nine minutes and persisting for the duration of the test. At the end of the examination the final rod threshold for the left eye was $1 \cdot 3 \log$ units higher than that of the right eye (Fig. 4).

\section{Electroretinography}

ERG studies were made in the routine manner of our laboratory. After dark adaptometry patients darkadapted for an additional 45 minutes. Burian-Allen contact lens electrodes were inserted under red light illumination after instilling proparacaine hydrochloride 0.05 per cent ophthalmic solution for corneal anaesthesia. White light stimuli of $20 \mathrm{~ms}$ duration recorded single and multiple flash responses. Dark-adapted eyes placed in Maxwellian view received the flashes via optical fibres from a tungsten lamp, with a Hartline shutter and a series of neutral density filters to vary stimulus intensity. Threshold responses were measured, beginning with subthreshold stimuli in single flashes. After about 30 seconds the next flash was presented. As the stimulus intensity increased the interval between single flashes was lengthened to about one minute to ensure the dark-adapted state. The intensity of the stimulus light was such as to generate a maximal bwave; the same light was used for both eyes, which were always recorded simultaneously. The patient's tracings showed normal $b$-waves on the right side and a highly abnormal, but barely recordable b-wave response on the left side (Fig. 5).

\section{Electro-oculography}

Electro-oculography was performed with the patient sitting in a darkened room for 45 minutes. Skin electrodes were attached at the medial and lateral canthi of each eye and in the centre of the forehead. A baseline response was recorded after one hour of dark adaptation. Each channel of the recording instrument was calibrated at $400 \mu \mathrm{V}$. The dark-adapted response was next measured for 12.5 minutes. With the eyes executing an excursion of 20 degrees at a distance of $\mathrm{I} \cdot 82 \mathrm{~m}$ from fixation targets the amplitude of the dark response was $1000 \mu \mathrm{V}$ for the right eye and $600 \mu \mathrm{V}$ for the left. Next, the lightadapted response was measured for 12.5 minutes. The 9 minutes reading was the maximum light rise. The normal right eye showed excursion amplitudes of $2200 \mu \mathrm{V}$ while the abnormal left eye showed the same amplitude, or no 'light rise' at all. Thus the Arden light-to-dark ratio of the normal right eye was $2 \cdot 2$, or 220 per cent, while the abnormal left eye showed a 


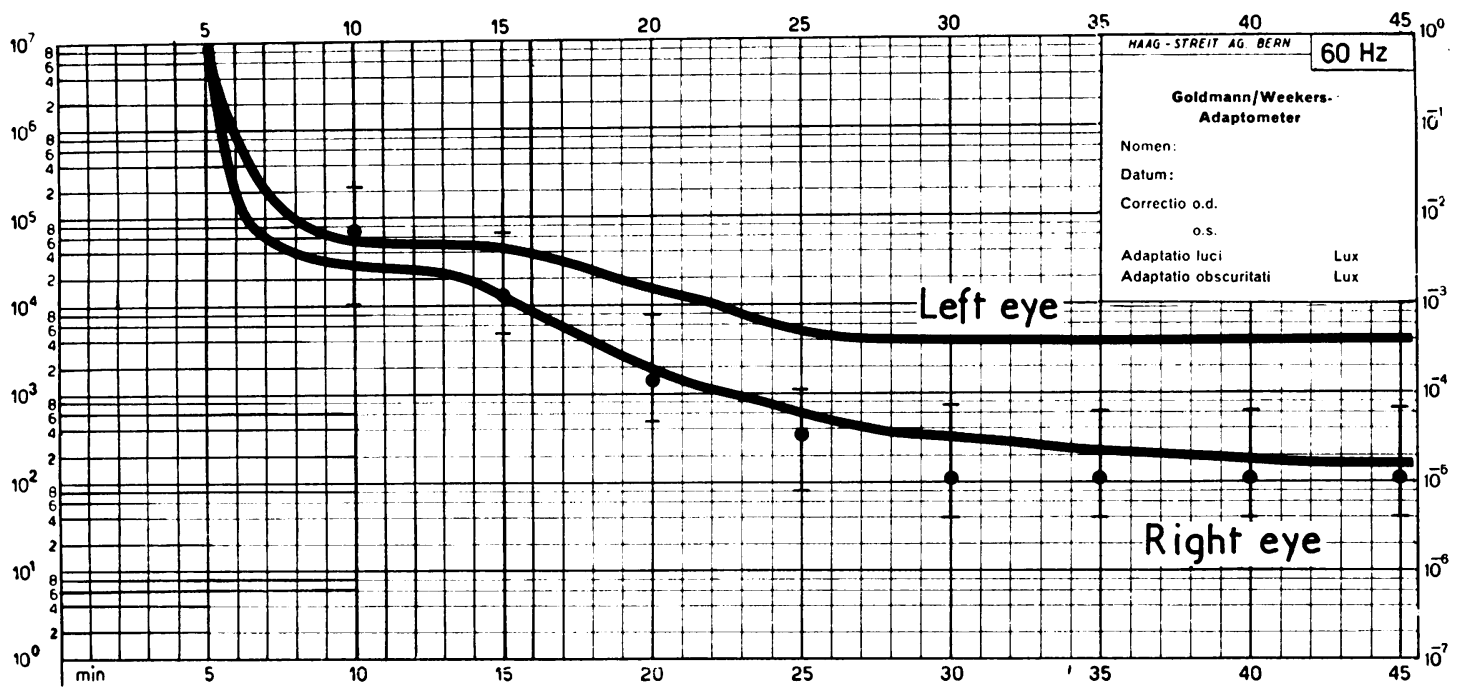

FIG. 4 Dark adaptation record showing raised threshold of the left eye compared with normal threshold of right eye. Difference of $1 \cdot 3 \log$ units in threshold indicates 50 -fold decrease in sensitivity of left eye. Initial cone portions of two curves (between 5 and $8 \mathrm{~min}$ ) were very similar. Dots and bars indicate normal mean ( $\pm 2 S D$ ) values for test in our laboratory

ratio of $\mathrm{I} \cdot 0$ or 100 per cent (Fig. 6). The EOG has been performed four times during the past 18 months. Since different instruments and protocols were used it is impossible to compare precisely the several tests, except to confirm the constant abnormality of the left eye as opposed to the normal right eye. The right eye has shown no evidence of functional impairment since our first contact with the patient.

\section{Discussion}

The diagnosis of retinitis pigmentosa sine pigmento from purely ophthalmoscopic findings is rather more difficult than in the more typical case of the
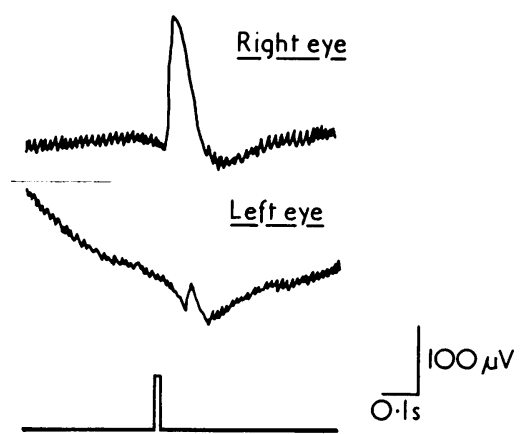

FIG. 5 Electroretinographic record of single flash simultaneously received by right eye (top) and left eve (bottom). Intensity used was equal for both eyes. Normal right eye shows small a-wave and large b-wave; affected left eye shows severely impaired $b$-wave disease with pigment deposition. Indeed, changes in the retinal pigment epithelial layer in the absence of pigment deposition are remarkably subtle and may easily escape detection. Optic pallor may be minimal or absent, as in this patient. Arteriolar attenuation was obvious in our case but may not be so in every case. Moreover, when evaluating the significance of arteriolar attenuation the possibility of a previous central retinal artery occlusion must be considered. This condition, we thought, could be ruled out in our case because of the patient's young age and the absence of any history of sudden, severe loss of vision on the affected side. Thus monocular constriction of the peripheral field in the presence of ipsilateral nightblindness may be the first diagnostic clue. Next, the finding of a grossly diminished b-wave or non-recordable ERG response on the one side and a normal response on the other lends additional weight to the impression of retinitis pigmentosa sine pigmento. And, finally, a unilaterally abnormal EOG supports the diagnosis even more strongly.

The amount of pigmentation in retinitis pigmentosa is variable. Pigment deposition can be sparse, moderate, or heavy-depending on any number of factors, including the patient's age, duration of the disease, and an individual proclivity, as it were, to deposit intraretinal pigment. Quite likely the sine pigmento state is one extreme of a wide spectrum of pigmentary patterns found in that group of diseases called 'retinitis pigmentosa' and not the manifestation of a separate or distinct 


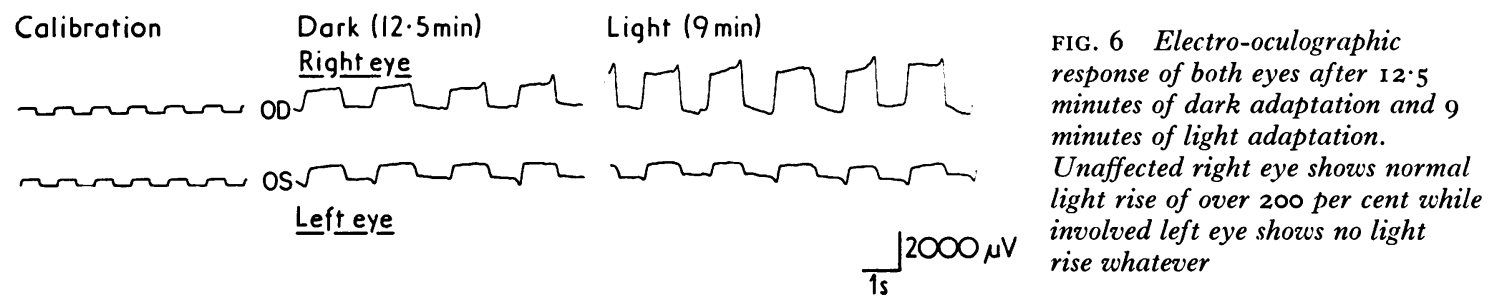

disorder. Our patient has been followed-up since March 1974 and still shows normal retinal function on the right side, but there is no guarantee that at some future time she may not develop bilateral disease or develop pigmentation on the currently affected side. Nevertheless, for the present the patient may be reasonably classified as an example of unilateral retinitis pigmentosa without pigment because all diagnostic criteria have been met.

\section{Summary}

A patient presented with unilateral findings of

night blindness shown by impaired rod function and dark adaptation, constricted visual fields with good central acuity, a barely recordable electroretinographic b-wave, and a unilaterally impaired electro-oculogram. There were none of the pigmentary changes usually associated with retinitis pigmentosa. The unaffected right eye was normal in all respects. Therefore the case is most probably one of unilateral retinitis pigmentosa sine pigmento.

We thank Mrs Nola J. Allston and Mr Robert Petrus for their technical assistance.

\section{References}

BERLINER, M. D. (I949) 'Biomicroscopy of the Eye', vol. 2, p. I439. Hoeber, New York

FRANCESCHETTI, A., FRANÇOIS, J., and BABEL, J. (1963) 'Les hérédo-dégénerescences chorio-rétiniènnes', p. 339. Masson \& Cie, Paris

HENkES, H. (1964) 'Proceedings of 3rd ISCERG Symposium', p. 327. Pergamon Press, Oxford JacoBson, J. H., and StePhens, G. (I962) Arch. Ophthal. (Chic.), 67, 96

RICKERS, J., and v. DOMARUS, D. (1974) Unilateral retinopathia pigmentosa. In 'Proceedings of the I Ith ISCERG

Symposium, Bad Nauheim', ed. E. Dodt and J. T. Pearlman, p. 513. Junk, The Hague Straub, w. (1966) Unilateral retinitis pigmentosa. 'Proceedings of 4th ISCERG Symposium', p. 278, vol. 10 Suppl. 